\title{
Effect of Income on Consumption of Different Food Commodities across Different Groups of Households of Tamil Nadu, India
}

\author{
K. Thomas Felix*, P. Naveen Kumar and D. David Rajasekar \\ Department of Agricultural Economics, Tamil Nadu Agricultural University, \\ Coimbatore-641003, India \\ *Corresponding author
}

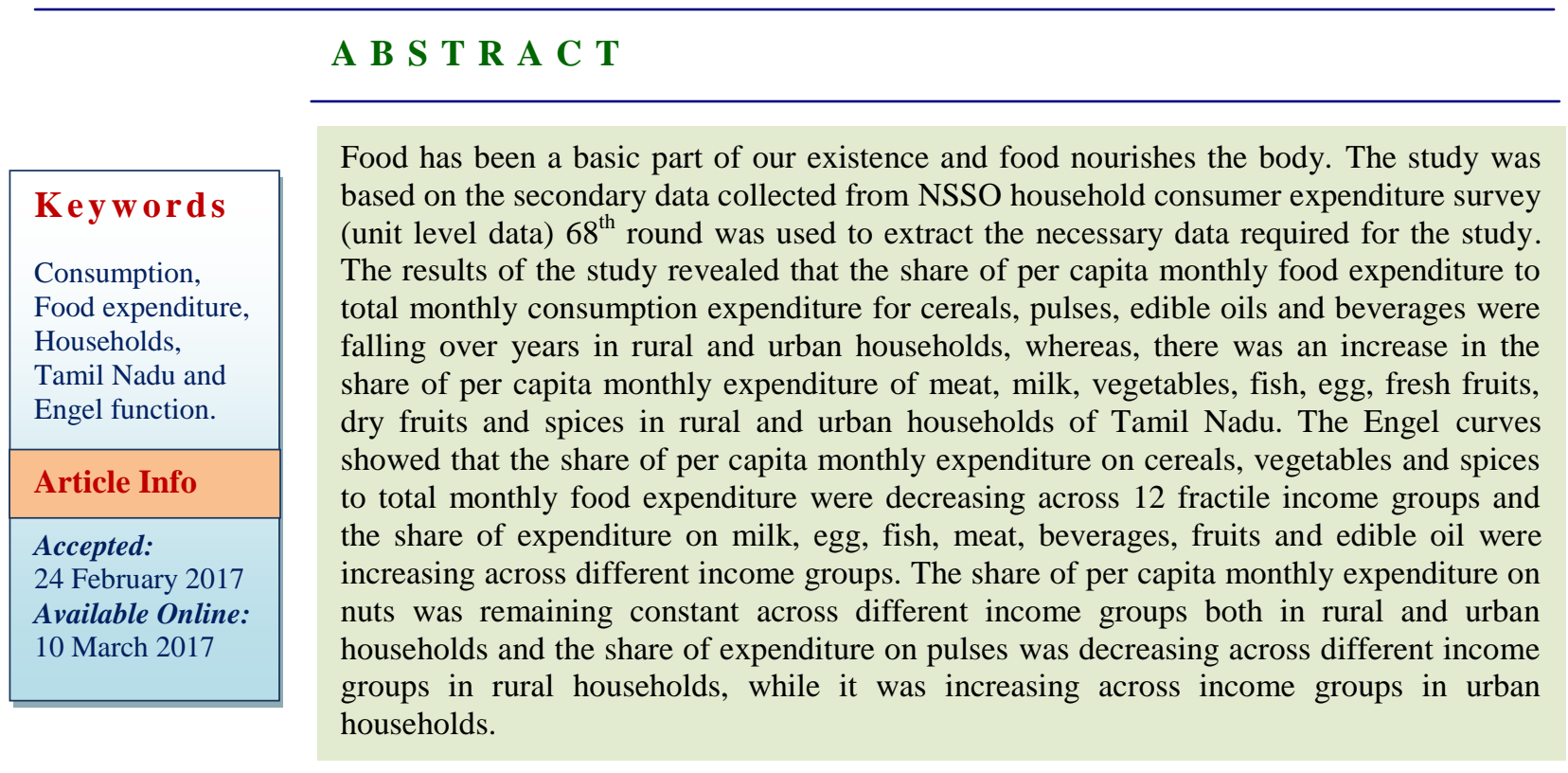

\section{Introduction}

Food has been a basic part of our existence and food nourishes the body. Food may be viewed as anything eaten or drunk, which meets the needs for energy, building, regulation and protection of the body. In short, food is the raw material from which our bodies are made. Intake of the right kind and amount of food can ensure good nutrition and health, which may be evident in our appearance, efficiency and emotional wellbeing. According to the report of Global Footprint Network (2012), if the current population and consumption trends continue, humanity will need the equivalent of two earths to support it by 2030. The world currently produces enough food for its citizens (FAO, 2011). However, food demand is only met in the aggregate, as there are profound disparities in access to food across geographic regions and across the spectrum of incomes at both the household and country levels. Kumar et al., (2011) examined the food demand in India in the context of a structural shift in the dietary pattern of its population. The results had reinforced the hypothesis of a significant diversification in 
the dietary pattern of households in recent years and found stark differences in the consumption pattern across different income quartiles. The analysis of annual growth rates on area, production and productivity of food crops in Tamil Nadu over decades revealed that there was a significant decline in the area from 1.96 percent in $1961-70$ to -0.91 percent in 2001-2010. Productivity of food grains showed a positive growth and it increased from 2.67 percent in 1961-70 to 6.72 percent in 2001-2010. The Tamil Nadu government has fixed a production target of 120 lakh tonnes of food grains in 2013. However, Tamil Nadu achieved a food grain production of 110.65 lakh tonnes (LT) in 2013-14. It may be due to shortfall of 33 percent in the NorthEast monsoon rains and the food grain production is expected to surpass 110 lakh metric tonnes in 2013-2014. Taking into consideration the above facts, the present study was undertaken to analyse the effect of income on consumption of different food commodities across different groups of households of Tamil Nadu.

\section{Materials and Methods}

Engel's consumption function: Linear Engel relationships may reflect the non-homothetic consumer preferences. As the high-income consumers may prefer to spend large portion of their income on high value food commodities such as meat, fish, milk, nuts and fruits a log-log form of the Engel equation was framed, which allows the income elasticity to vary across the different income classes:

The Engel function specified for the study is: $\ln w_{i}=\alpha_{i}+\gamma_{i} \ln y_{i}+u_{i}$

Where, the dependent variable wi represents the share of ith commodity in the total budget. The independent variable yj represents the per capita income of households, and uij is a random disturbance term. The parameters $\alpha \mathrm{i}$, $\gamma \mathrm{i}$, ui are to be estimated. Where $\alpha \mathrm{i}$ is the constant, $\gamma \mathrm{i}$ is the expenditure elasticity, ui is the error term. The Engel function was estimated by regressing the share of average monthly per capita consumption expenditure of different food items to total household food expenditure share of individual food item on the per capita monthly income of the households across 12 fractile groups. After estimation of the parameters, the predicted value of wi for food item across different income groups (12 fractile groups) were plotted as Engel curves. This study was based on the secondary data collected from NSSO household consumer expenditure survey (unit level data) $68^{\text {th }}$ round was used to extract the necessary data required for the study.

\section{Results and Discussion}

Engel curves - the effect of income on consumption of different food items in rural and urban households

Engel functions were fitted for 12 individual commodity groups both for rural and urban households by taking share of individual commodity group in the total budget as dependent variable and the per capita income of households across 12 fractile classes as independent variable. After estimation of the parameters, the predicted value of Wi (share of individual commodity group across 12 fractile income groups were calculated and plotted as Engel curves for 12 commodity groups.

The Engel curves derived for cereals in rural and urban households are presented as figures 1 and 2.

From figures 1 and 2, the share of monthly expenditure on cereals to total monthly food expenditure across income groups in rural and urban households indicated that the 
proportion of income allocation on necessary good such as cereals was high in low income groups and decreasing continuously across different income groups in the order of low income class to high income class. This was in lines with the theory that income or expenditure elasticity of necessary goods would be inelastic in nature. The examination of shape of the of predicted share of cereals revealed that the share of cereals was decreasing steeply in rural households than in urban households, indicating that income demand for cereals was more inelastic in rural households than in urban households

\section{Engel curve for pulses in rural and urban households of Tamil Nadu}

From figures 3 and 4, the share of monthly expenditure on pulses to total monthly food expenditure across income groups in rural and urban households indicated that the proportion of income allocation on pulses was decreasing across different income groups in rural households, while proportion of income allocation on pulses was increasing across the across different the income groups in urban households. This elastic income demand for pulses in urbanities may be due to the shift to high valued and highly priced pulses and pulse based processed products in their consumption pattern. The expected inelastic demand was proved in the case of rural households where, there was a reduction in the share of expenditure with the increase in income.

\section{Engel curve for milk in rural and urban households of Tamil Nadu}

From figures 5 and 6 , the share of monthly expenditure on milk to total monthly food expenditure across income groups in rural and urban households indicated that the proportion of income allocated on milk which is a normal good was increasing across different income groups, proving the theory that normal and superior goods would have elastic income demand. The examination of shape of the of predicted share of milk revealed that the line was increasing steeply for urban households than in rural households, indicating that income demand for milk was more elastic in urban households than in rural households.

Engel curve for edible oil in rural and urban households of Tamil Nadu

From figures 7 and 8 , the share of monthly expenditure on milk to total monthly food expenditure across income groups in rural and urban households indicated that the proportion of income allocated on milk which is a normal good was increasing across different income groups, proving the theory that normal and superior goods would have elastic income demand. The share of monthly expenditure on edible oil to total monthly food expenditure across income groups in rural and urban households indicated that the proportion of income allocated on edible oil which is a normal good was increasing across different income groups, proving the theory that normal and superior goods would have elastic income demand. The examination of shape of the of predicted share of edible oil revealed that it was increasing steeply for urban households than in rural households, indicating that income demand for edible oil was more elastic in urban households than in rural households.

\section{Engel curve for meat in rural and urban household of Tamil Nadu}

From figures 9 and 10, the share of monthly expenditure on meat to total monthly food expenditure across income groups in rural and urban households indicated that the proportion of income allocated on meat which is a normal good was increasing across 
different income groups, proving the theory that normal and superior goods would have elastic income demand.

The examination of shape of the predicted share of meat revealed that the line was increasing steeply for urban households than in for rural households, indicating that income demand for meat was more elastic in urban households than in rural households.

\section{Engel curve for fish in rural and urban households of Tamil Nadu}

From figures 11 and 12, the share of monthly expenditure on fish to total monthly food expenditure across income groups in rural and urban households indicated that the proportion of income allocated on fish which is a normal good was slightly increasing across different income groups, proving the theory that normal goods would have elastic income demand. The examination of shape of the of predicted share of fish revealed that the line was increasing slightly for both rural and urban households, indicating that income demand for fish was relatively elastic in both rural and urban households.

\section{Engel curve for eggs in rural and urban households of Tamil Nadu}

From figures 13 and 14, the share of monthly expenditure on eggs to total monthly food expenditure across income groups in rural and urban households indicated that the proportion of income allocated on eggs, which is a normal good was slightly increasing across different income groups, proving the theory that normal and superior goods would have elastic income demand.

The examination of shape of the of predicted line of share of eggs revealed that the line was increasing slightly for both rural and urban households, indicating that income demand for eggs was relatively elastic in both rural and urban households.

Engel curve for vegetables in rural and urban households of Tamil Nadu

From figures 15 and 16, the share of monthly expenditure on vegetables to total monthly food expenditure across income groups in rural and urban households indicated that the proportion of income allocation on inferior good such as vegetables was high in low income groups and decreasing continuously across different income groups in the order of low income class to high income class. This was in line with the theory that income or expenditure elasticity of necessaries would be in elastic in nature. The examination of shape of the of predicted share of vegetables revealed that the line was decreasing steeply for rural households than in urban households, indicating that income demand for vegetables was more inelastic in rural households than in urban households
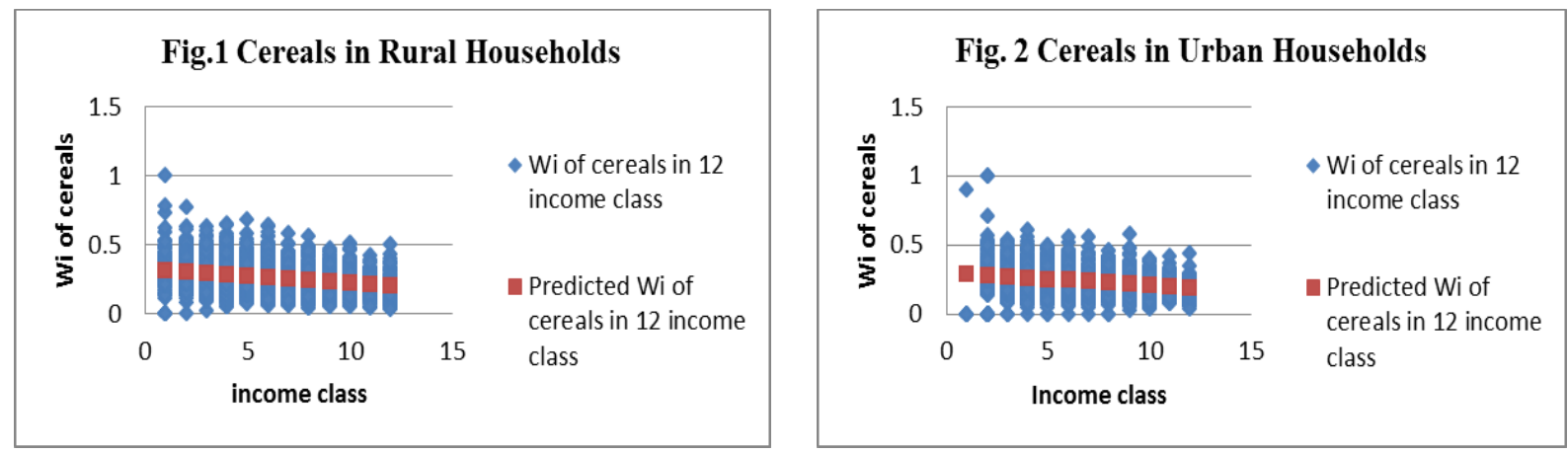

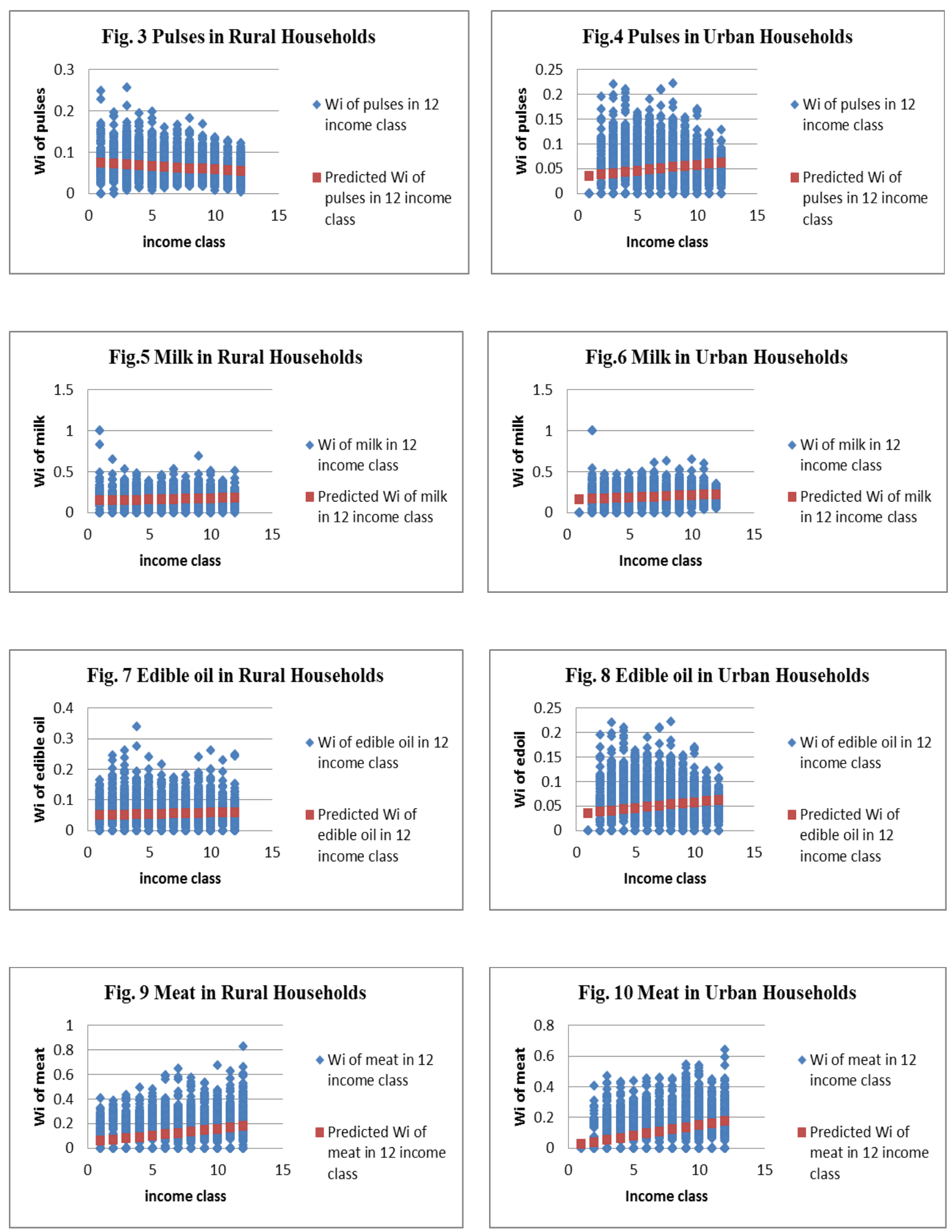

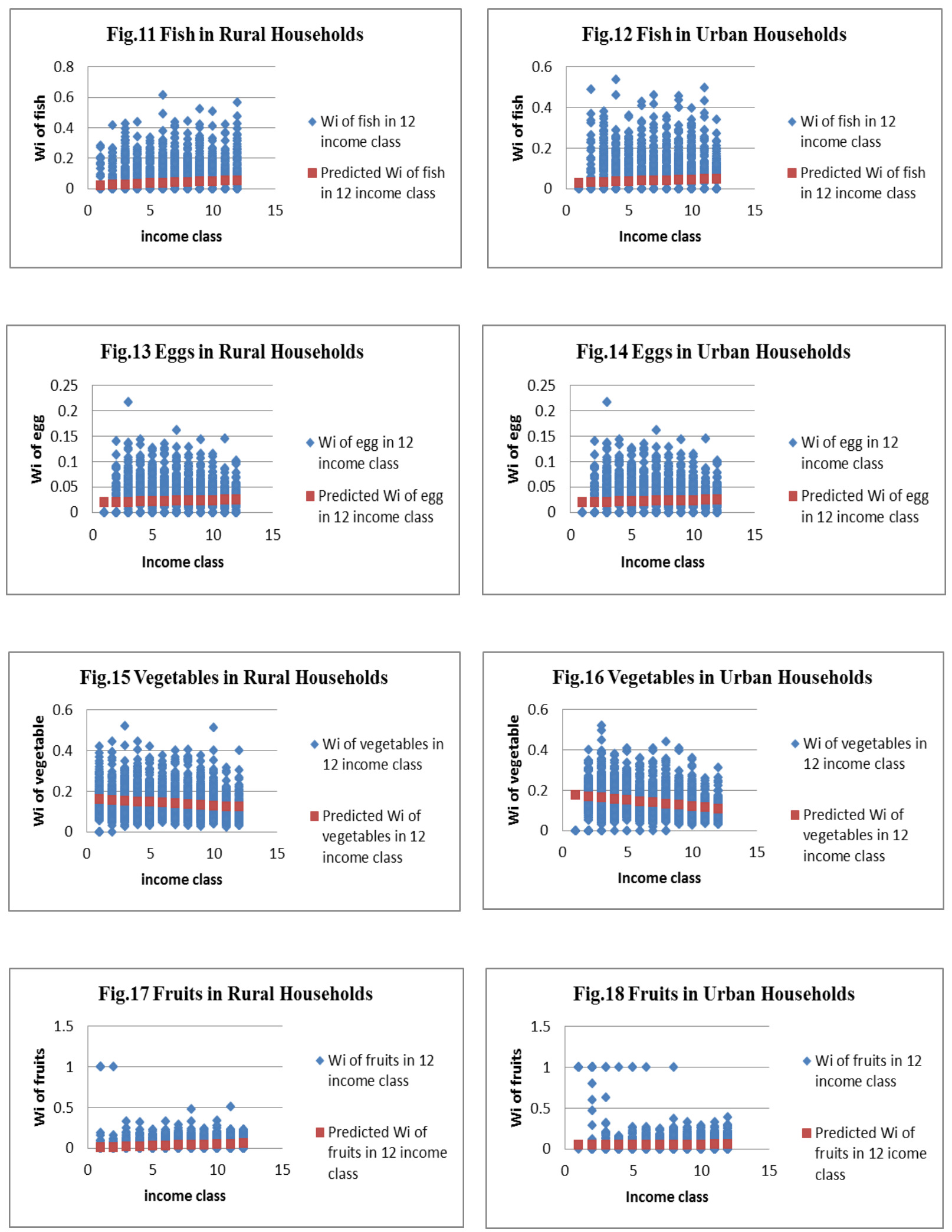

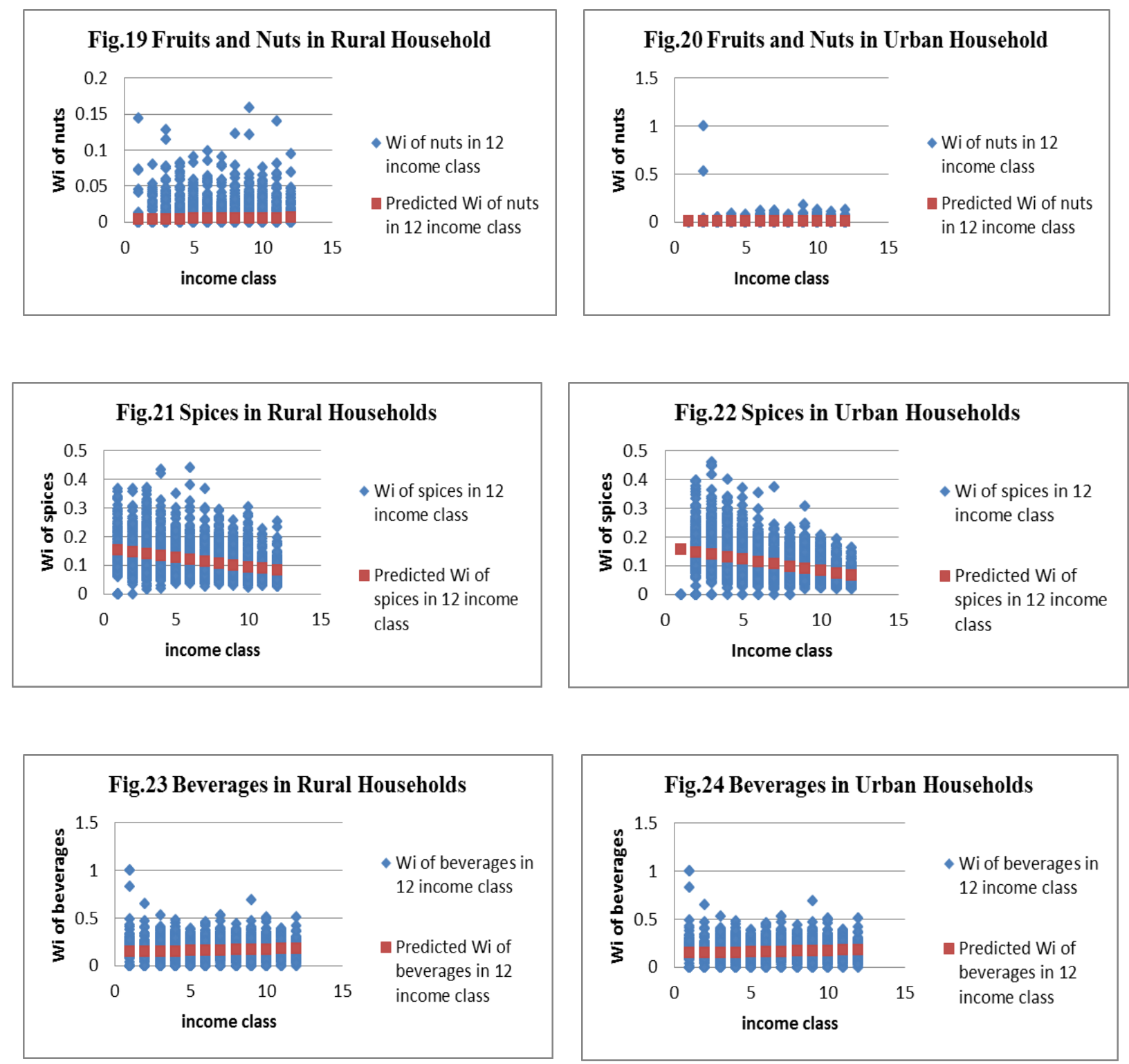

Engel curve for fruits in rural and urban households of Tamil Nadu

From figures 17 and 18, the share of monthly expenditure on fruits to total monthly food expenditure across income groups in rural and urban households indicated that the proportion of income allocated on fruits which is a normal good was slightly increasing across different income groups, proving the theory that normal goods would have elastic income demand. The examination of shape of the predicted share of fruits revealed that the line was increasing slightly

for both rural and urban households, indicating that income demand for fruits was relatively elastic in both rural and urban households.

\section{Engel curve for dry fruits and nuts in rural and urban household of Tamil Nadu}

From figure 19 and 20, the share of monthly expenditure on dry fruits and nuts to total monthly food expenditure across income groups in rural and urban household indicated that the proportion of income allocated on dry fruits and nuts was more or less remaining 
constant, indicating a constant income demand. The examination of shape of the of predicted share of dry fruits and nuts revealed that the line was remaining constant for both rural and urban households, indicating that income demand for dry fruits and nuts was relatively constant both in rural and urban households.

\section{Engel curve for spices in rural and urban households of Tamil Nadu}

From figures 21 and 22, the share of monthly expenditure on spices to total monthly food expenditure across income groups in rural and urban households indicated that the proportion of income allocation on necessary good such as spices was high in low income groups and decreasing continuously across different the income groups in the order of low income class to high income class. This was in line with the theory that income or expenditure elasticity of necessary goods would be positive but inelastic in nature.

The examination of shape of the of predicted share of spices revealed that the line was decreasing steeply in urban households than in rural households, indicating that income demand for spices was more inelastic in urban households than in rural households.

\section{Engel curve for beverages in rural and urban households of Tamil Nadu}

From figures 23 and 24, the share of monthly expenditure on beverages to total monthly food expenditure across income groups in rural and urban households indicated that the proportion of income allocated on beverages which is a normal good was slightly increasing across different income groups, proving the theory that normal goods would have elastic income demand. The examination of shape of the predicted share of beverages revealed that the line was increasing slightly for both rural and urban households, indicating that income demand for beverages was elastic in both rural and urban households.

In conclusion the analysis of Engel curve and the behaviour of predicted share the of expenditure of food groups for change in household income across 12 fractile income groups indicated that share of expenditure on cereals, vegetables and spices were decreasing across the income groups both in rural and urban areas; the share of expenditure on pulses was decreasing across the income groups in rural and increasing across the income groups in rural urban areas and the share of expenditure on milk, egg, fish, meat, beverages, fruits, nuts and edible oil were increasing across the income groups both in rural and urban areas of Tamil Nadu, which indicated that the household food demand in terms of share of expenditure varied across different food groups and also across regions in terms of urban and rural households in Tamil Nadu.

\section{Acknowledgement}

My words are weak to express my indebtedness to my Chairman, Dr. D. David Rajasekar, Professor, Department of Agricultural Economics, Tamil Nadu Agricultural University, Coimbatore. Grace of almighty has always been felt in having given me this unique, dexterous personality to guide and inspire me with his soft, sincere, valuable suggestions, to pen this thesis. I owe him a lot for ever.

\section{References}

Abdul, A.A., Gabrel, D., Sadiqy, A. Moblazi, L.F. and Unoruoyiza, M.M. 2015. Lumbosacral epidural analgesia with ketamine alone with combination with xylazine in dogs. Int. J. Vet. Sci., 4(3): 
111-117.

Aithal, H.P., Amarpal, Singh, G.R. 1998. Epidural use of ketamine for hindquarter analgesia in dogs. Indian $J$. Animal Sci., 68(6): 554.

Amarpal, Aithal, H.P., Kinjavdekar, P. and Singh, G.R. 1997. Clinical effects of epidural ketamine and pethidine in dogs. 21 Annual Congress of I.S.V.S., Palampur, Abstract no. 30.

Atalan, G., Uzun, M., Demirkan, I., Yildiz, S., and Cenesiz, M. 2002. Effect of Medetomidine-Butorphanol-Ketamine Anaesthesia and Atipamezole on Heart and Respiratory Rate and Cloacal Temperature of Domestic Pigeons. J. Vet. Med., A 49(6): 281-285.

Booth, N.H. 1981. Veterinary Pharmacology and Therapeutics, 4th edn., ed. by L. Mayer Jones, Nicholas H. Booth, W. Both, Leslie E. McDonald. Oxford and IBH Published Co. New Delhi, Bombay and Calcuta, 436-445.

Cousins, M.J. and Mather, L.E. 1984. Intrathecal and epidural administration of opioids. Anesthesiol., 61(3): 276-310.

De Rossi, R., Sampaio, B.F.B., Varela, J.V. and Junqueira, A.L. 2004. Perineal analgesia and hemodynamic effects of the epidural administration of meperidine or hyperbaric bupivacaine in conscious horse. Canadian Vet. J., 45(1): 42-47.

DeRossi, R., Benites, A.P., Ferreira, J.Z., Neto, J.M. and Hermeto, L.C. 2009. Effects of lumbosacral epidural ketamine and lidocaine in xylazinesedated cats. J. S. Afr. Vet. Assoc., 80: 79-83.

Erol, I.M., Özdogan, L., Örnek, D., Tas, V., Kalaycı, D., Barçın, S., Sahin, F., Erk, G. and Dikmen, B. 2014. Effect of ketamine on the quality of anesthesia and postoperative analgesia in epidural anesthesia. JECM, 6: 83-89.

Folts J.D., Afonso, S. and Rowe, G.G. 1975. Systemic and coronary haemodynamic effects of ketamine in intact anaesthetized and unanaesthetized dogs. Br. J. Anaesth., 47(6): 686-94.

Freeman, J. 1962. Survival of bled dogs after halothane and ether anaesthesia. Br. J. Anaesth., 34: 832

Geddes, L.A., Combs, W. and Denton, W. 1980. Indirect mean arterial pressure in the anaesthetized dog. Am. J. Physiol., 238: 664-666.

\section{How to cite this article:}

Thomas Felix, K., P. Naveen Kumar and David Rajasekar, D. 2017. Effect of Income on Consumption of Different Food Commodities across Different Groups of Households of Tamil Nadu, India. Int.J.Curr.Microbiol.App.Sci. 6(3): 2256-2264.

doi: http://doi.org/10.20546/ijcmas.2017.603.258 